\title{
Cannabidiol induces expression of human cytochrome P450 1A1 that is possibly mediated through aryl hydrocarbon receptor signaling in HepG2 cells
}

Satoshi Yamaori ${ }^{\mathrm{a}}$, Yuka Kinugasa ${ }^{\mathrm{b}}$, Rongrong Jiang ${ }^{\mathrm{b}}$, Shuso Takeda ${ }^{\mathrm{c}, 1}$, Ikuo Yamamoto ${ }^{\mathrm{d}}$, Kazuhito Watanabe $e^{\mathrm{b}, \mathrm{c}, *}$

${ }^{\mathrm{a}}$ Department of Pharmacy, Shinshu University Hospital, 3-1-1 Asahi, Matsumoto 390-8621, Japan.

${ }^{\mathrm{b}}$ Department of Hygienic Chemistry, Faculty of Pharmaceutical Sciences, Hokuriku University, Ho-3, Kanagawa-machi, Kanazawa 920-1181, Japan.

${ }^{\circ}$ Organization for Frontier Research in Preventive Pharmaceutical Sciences, Hokuriku University, Ho-3, Kanagawa-machi, Kanazawa 920-1181, Japan.

${ }^{\mathrm{d} D e p a r t m e n t ~ o f ~ H y g i e n i c ~ C h e m i s t r y, ~ S c h o o l ~ o f ~ P h a r m a c e u t i c a l ~ S c i e n c e s, ~ K y u s h u ~ U n i v e r s i t y ~}$ of Health and Welfare; 1714-1 Yoshino-machi, Nobeoka 882-8508, Japan.

*Correspondence to:

Kazuhito Watanabe, Ph.D.

Department of Hygienic Chemistry

Faculty of Pharmaceutical Sciences

Hokuriku University

Ho-3, Kanagawa-machi, Kanazawa 920-1181, Japan

Tel: +81 76-229-6220, Fax: +81 76-229-6220

E-mail address: k-watanabe@hokuriku-u.ac.jp 


\section{ABSTRACT}

Aims: We herein investigated the inducibility of cytochrome P450 1A1 (CYP1A1) by $\Delta^{9}$-tetrahydrocannabinol, cannabidiol (CBD), and cannabinol, three major phytocannabinoids, using human hepatoma HepG2 cells.

Main methods: The expression of CYP1A1 and the aryl hydrocarbon receptor (AhR) was measured by a quantitative real-time polymerase chain reaction and/or Western blotting.

Key findings: $\Delta^{9}$-Tetrahydrocannabinol and CBD concentration-dependently induced the expression of CYP1A1 mRNA, whereas cannabinol showed little or no induction. Among the phytocannabinoids tested, CBD was the most potent inducer of CYP1A1 expression. The induction of CYP1A1 expression by CBD was significantly attenuated by the knockdown of AhR expression with $\mathrm{AhR}$ small interfering RNAs. The role of protein tyrosine kinases (PTKs) in the CBD-mediated induction of CYP1A1 was then examined using herbimycin A, a PTK inhibitor. The upregulation of CYP1A1 by CBD was significantly suppressed by herbimycin $\mathrm{A}$ as was the induction by omeprazole but not 3-methylcholanthrene. The inducibility of CYP1A1 by CBD-related compounds was examined to clarify the structural requirements for CBD-mediated CYP1A1 induction. Olivetol, which corresponds to the pentylresorcinol moiety of CBD, significantly induced the expression of CYP1A1, whereas $d$-limonene, CBD-2 -monomethyl ether, and CBD-2 ,6 -dimethyl ether did not.

Significance: These results showed that CBD may have induced human CYP1A1 expression through the activation of PTK-dependent AhR signaling, in which two phenolic hydroxyl groups in the pentylresorcinol moiety of CBD may play structurally important roles.

Keywords: marijuana; cannabidiol; CYP1A1; induction; AhR; protein tyrosine kinase. 


\section{Introduction}

Marijuana is the most widely used illicit drug in the world. Its use is a growing public health concern due to potential adverse effects such as dependence, association with polysubstance use, increased risk of motor vehicle crashes, impaired respiratory function, cardiovascular disease, and various health consequences [1]. Marijuana leaves contain at least 70 cannabinoids [2], with $\Delta^{9}$-tetrahydrocannabinol $\left(\Delta^{9}\right.$-THC), cannabidiol (CBD), and cannabinol $(\mathrm{CBN})$ being the three main constituents (Fig. 1). $\Delta^{9}-\mathrm{THC}$ is the principal psychoactive component of marijuana and has various pharmacological effects such as catalepsy, hypothermia, antiinflammation, and antinociception [3]. CBD is not psychoactive, but has several pharmacological effects such as antiepileptic, anxiolytic, and antiemetic actions [4]. CBN is believed to exert minimal pharmacological effects on the central nervous system.

Marijuana is commonly consumed by smoking. Previous studies reported that habitual smokers of marijuana exhibited molecular and histopathological changes that were similar to precancerous lesions observed in the bronchial epithelium of tobacco smokers $[5,6]$. Furthermore, an epidemiological study revealed a correlation between marijuana use and head and neck cancer [7]. These findings suggest that a history of marijuana use may increase the risk of developing cancer. Marijuana smoke includes various procarcinogenic polycyclic aromatic hydrocarbons (PAHs) such as benzo $[a]$ pyrene $(\mathrm{B}[a] \mathrm{P})$ and benz $[a]$ anthracene $[8-10]$. These PAHs are metabolically activated by cytochrome P450s (CYPs) to exert genotoxicity and carcinogenicity [11]. For example, $\mathrm{B}[a] \mathrm{P}$ is metabolized by CYP1A1 and epoxide 
hydrolase to a diol-epoxide, the ultimate carcinogen, the formation of DNA adduct by which plays a critical role in tumor initiation [12]. Some PAHs are also known to potently induce the expression of CYP1A1 [11]. These findings indicated that the potency of the catalytic activity of CYP1A1 and its expression levels are important risk factors for determining cancer induced by marijuana use. Witschi and Saint-François [13] demonstrated that $\mathrm{B}[a] \mathrm{P}$ hydroxylase activity, an index of CYP1 activity, was increased in the lung homogenates of rats administered $\Delta^{9}$-THC. Furthermore, $\Delta^{9}$-THC has been shown to induce the expression of CYP1A1 in mouse hepatoma Hepa-1 cells, primary human airway epithelial cells, and human breast cancer MDA-MB-231 cells [14-16]. Phytocannabinoids are present in marijuana smoke at markedly higher concentrations than PAHs $[8,9,14]$. A previous study estimated that the content of $\Delta^{9}$-THC was approximately $9.3 \mathrm{mg}$ per marijuana cigarette whereas the contents of $\mathrm{B}[a] \mathrm{P}$ and benz $[a]$ anthracene were 22 and 56 ng per marijuana cigarette, respectively [14]. Thus, phytocannabinoids may also contribute to the induction of CYP1A1 by marijuana components. However, it currently remains unclear whether major phytocannabinoids other than $\Delta^{9}$-THC, i.e. CBD and CBN, induce the expression of CYP1A1.

In the present study, we examined the inducibility of human CYP1A1 by the three major phytocannabinoids $\left(\Delta^{9}-\mathrm{THC}, \mathrm{CBD}\right.$, and $\left.\mathrm{CBN}\right)$. We showed that $\mathrm{CBD}$ was the most potent inducer of the expression of CYP1A1 in human hepatoma HepG2 cells. Furthermore, the results of our study suggest that the induction of CYP1A1 by CBD was mediated through aryl hydrocarbon receptor (AhR) signaling via the activation of protein tyrosine kinases (PTKs). 


\section{Materials and methods}

Materials

$\Delta^{9}-\mathrm{THC}, \mathrm{CBD}$, and $\mathrm{CBN}$ were isolated from cannabis leaves using a previously reported method [17]. CBD-2 -monomethyl ether (CBDM) and CBD-2,6-dimethyl ether (CBDD) were prepared as described previously [18]. The purities of these cannabinoids were determined to be above $97 \%$ by gas chromatography, except for CBDD, the purity of which was 93\% [19]. Other chemicals and materials were obtained from the following sources: olivetol, $d$-limonene, and an anti-actin (20-33) antibody produced in rabbits from Sigma-Aldrich (St. Louis, MO); 3-methylcholanthrene (3-MC) and omeprazole from Wako Pure Chemical Industries, Ltd. (Osaka, Japan); herbimycin A from Funakoshi (Tokyo, Japan); a rabbit polyclonal antibody against human AhR (H-211) from Santa Cruz Biotechnology, Inc. (Santa Cruz, CA). All other chemicals and solvents used were of the highest quality commercially available.

\section{Cell culture and drug treatments}

The human hepatoma HepG2 cell line was obtained from the RIKEN cell bank (Tsukuba, Japan). These cells were maintained in minimum essential medium Eagle containing nonessential amino acids (Sigma-Aldrich) supplemented with $10 \%$ fetal bovine serum (BioWest, Nuaillé, France) and penicillin/streptomycin (Gibco, Grand Island, NY) in a humidified atmosphere containing $5 \% \quad \mathrm{CO}_{2}$ at $37^{\circ} \mathrm{C}$. Cultures of approximately $80 \%$ 
confluence in a 100-mm culture dish were used to seed for the following experiments. Cells were seeded into a 6 -well plate $\left(1 \times 10^{6}\right.$ cells/well $)$ and $35-\mathrm{mm}$ culture dish $\left(0.2 \times 10^{6}\right.$ cells/dish) and cultured for $24 \mathrm{hr}$. Cells were then treated with phytocannabinoids, CBD-related compounds, 3-MC, or omeprazole in serum-free medium for up to $12 \mathrm{hr}$. Inhibition experiments were performed as described below. Cells were pretreated with herbimycin A for $12 \mathrm{hr}$ before treatment with the test compounds including CBD. Phytocannabinoids and other test chemicals were prepared in ethanol and/or dimethyl sulfoxide (DMSO). Control incubations had equivalent additions of ethanol and/or DMSO. Ethanol and/or DMSO did not markedly influence cell viability at the final volume used.

\section{RNA interference}

Reverse transfections were carried out in $35-\mathrm{mm}$ culture dishes $\left(0.2 \times 10^{6}\right.$ cells/dish $)$ using Silencer ${ }^{\circledR}$ Select Validated small interfering RNAs (siRNAs) for human AhR (ID\# s1199 and s1200), Silencer ${ }^{\circledR}$ Negative Control \#1 siRNA, and siPORT ${ }^{\mathrm{TM}}$ NeoFX $X^{\mathrm{TM}}$ transfection agent (Ambion, Austin, TX) according to the manufacturer's instructions. Forty-eight hours after transfection with siRNA, HepG2 cells were treated with CBD and 3-MC for 6 and $3 \mathrm{hr}$, respectively.

\section{RNA analysis}

Total RNA was extracted from HepG2 cells using ISOGEN reagent (Nippon Gene, Toyama, Japan). Reverse transcriptase reactions were performed with the SuperScript ${ }^{\mathrm{TM}}$ III 
First-strand Synthesis SuperMix for qRT-PCR (Invitrogen, Carlsbad, CA). A quantitative real-time polymerase chain reaction (qPCR) was conducted using an ABI 7500 real-time PCR system (Applied Biosystems, Foster City, CA) with Platinum ${ }^{\circledR}$ SYBR $^{\circledR}$ Green qPCR SuperMix-UDG qPCR (Invitrogen) according to the manufacturer's instructions. The primers used for mRNA measurements were as follows: CYP1A1, 5 -GTCATCTGTGCCATTTGCTTTG-3 and 5-CAACCACCTCCCCGAAATTATT-3 ;

AhR, 5 -TGGACAAGGAATTGAAGAAGC-3 and 5 -AAAGGAGAGTTTTCTGGAGGAA-3. Values were quantified by the comparative Ct method, and samples were normalized to $\beta$-actin; 5 -ATTGCCGACAGGATGCAGA-3 and 5 -GCTCAGGAGGAGCAATGATCTT-3 .

\section{Western blot analysis}

Whole cell lysates were prepared from HepG2 cells $48 \mathrm{hr}$ after transfection with siRNA as described previously [20]. SDS-PAGE was performed using 7.5\% acrylamide gels as described previously [21]. Total cellular protein (10 $\mu \mathrm{g}$ protein) was separated and transferred onto a PVDF membrane. Immunodetection was performed using anti-human AhR and anti-actin antibodies as primary antibodies and horseradish peroxidase-conjugated anti-rabbit immunoglobulin (Amersham Biosciences Inc., Piscataway, NJ) as a secondary antibody. Conjugated horseradish peroxidase was detected using Immobilon ${ }^{\mathrm{TM}}$ Western Chemiluminescent HRP Substrate (Millipore, Billerica, MA), and bands were scanned with ChemiDoc XRS (Bio-Rad Laboratories, Richmond, CA). 
Statistical analysis

The significance of differences between the means of the various groups was evaluated by means of a one-way analysis of variance followed by Bonferroni or Dunnett's post-hoc test. All statistical analyses were carried out with the program InStat (GraphPad Software, San Diego, CA).

\section{Results}

Inducibility of human CYP1A1 expression by $\Delta^{9}-T H C, C B D$, and CBN in HepG2 cells

To characterize the inducibility of human CYP1A1 by phytocannabinoids, the effects of $\Delta^{9}$-THC, CBD, and CBN on CYP1A1 expression levels were evaluated with HepG2 cells. $\Delta^{9}$-THC and CBD increased the expression of CYP1A1 mRNA in a concentration-dependent manner; CYP1A1 mRNA levels at $50 \mu \mathrm{M} \Delta^{9}$-THC and CBD were 1.7- and 4.8-fold higher, respectively, than control levels (Figs. 2A and 2B). In contrast, $\mathrm{CBN}$ had a less marked effect on CYP1A1 expression (Fig. 2C). CYP1A1 mRNA expression levels reached a maximum 6 hr after the treatment with $\mathrm{CBD}$ and then decreased (Fig. 2D). Under the current conditions, $\Delta^{9}$-THC, CBD, and CBN did not influence the viability of HepG2 cells, as assessed by the MTT and LDH assays (data not shown).

Role of AhR in CBD-mediated induction of human CYP1A1

The transcriptional activation of the CYPIAl gene is mediated by the AhR, which is 
a transcription factor of the basic-helix-loop-helix/Per-Arnt-Sim family [22]. To clarify whether the AhR was responsible for the induction of CYP1A1 by CBD, inducibility by CBD was investigated using AhR knocked-down cells. When HepG2 cells were transfected with AhR siRNA (ID\# s1199), the expression of AhR was effectively diminished at the mRNA and protein levels (Figs. 3A and 3B). The knockdown of AhR expression with AhR siRNA significantly suppressed CYP1A1 expression levels induced by 3-MC (Fig. 3C). This knockdown also efficiently reduced the CBD-mediated induction of CYP1A1 expression (Fig. 3D). These knockdown results were similarly observed in cells introducing another AhR siRNA (ID\# s1200) (data not shown).

Role of PTKs in CBD-mediated induction of human CYP1A1

The transcriptional activation of the CYPIAl gene through the AhR involves at least two mechanisms; a ligand-dependent AhR activation by AhR agonists such as 3-MC [22] and ligand-independent activation of PTK-dependent AhR signaling by omeprazole [23-25]. To clarify the role of PTKs in the induction of CYP1A1 by CBD, the effects of herbimycin A, a PTK inhibitor, on inducibility by CBD were examined and compared with those by omeprazole and 3-MC. The induction of CYP1A1 expression by omeprazole was effectively suppressed by herbimycin A (Fig. 4A), whereas 3-MC-mediated induction was not influenced by this inhibitor (Fig. 4B). The upregulated expression of CYP1A1 by CBD was significantly decreased by herbimycin A (Fig. 4C), as was the case by omeprazole. 
Structural requirements for CBD-mediated induction of human CYP1A1

To elucidate the structural requirements for CYP1A1 inducibility by CBD, the effects of CBD-related compounds (Fig. 5A) on CYP1A1 expression levels were investigated using HepG2 cells. Olivetol, which corresponds to the pentylresorcinol moiety of CBD, significantly upregulated the expression of CYP1A1 (Fig. 5B), whereas $d$-limonene, which corresponds to the terpene moiety of CBD, did not. Furthermore, CBDM and CBDD, which are the monomethylated and dimethylated derivatives of $\mathrm{CBD}$, respectively, did not significantly induce CYP1A1.

\section{Discussion}

Previous studies on the inducibility of CYP expression by marijuana components have been conducted using experimental animals and cultured cells. Cannabis resin, marijuana tar, and $\Delta^{9}$-THC have been shown to induce the expression of CYP1A enzymes [13-16]. We herein demonstrated that CBD induced the expression of CYP1A1 in HepG2 cells; inducibility by CBD was more potent than that by $\Delta^{9}-\mathrm{THC}$. To the best of our knowledge, this is the first study to show the induction of CYP1A expression by CBD; however, the phytocannbinoid is known to be an inducer of CYP2B and CYP3A enzymes in mouse livers [26]. The mean contents of $\Delta^{9}$-THC and CBD in dried plant preparations of marijuana confiscated in the United States were estimated to be $4.5 \%$ and $0.4 \%$, respectively, although these contents varied widely [27]. In marijuana resin, which is commonly referred to as hashish, the average contents of $\Delta^{9}$-THC and CBD were $14.1 \%$ and $2.5 \%$, respectively [27]. 
The plasma profiles of $\Delta^{9}$-THC and CBD after smoking a marijuana cigarette were shown to be similar $[28,29]$. When the inducibility of CYP1A1 expression and the relative contents of these phytocannabinoids are considered, CBD and $\Delta^{9}$-THC may contribute to the induction of CYP1A1 by marijuana components.

As shown in Fig. 2D, CYP1A1 mRNA expression levels in the control group transiently increased after the change to a serum-free medium without CBD. This was not attributed to the induction of $\mathrm{AhR}$ expression by serum starvation because AhR mRNA expression levels were not changed by the removal of serum from medium (data not shown). Feng et al. [30] have shown that the expression of CYP1A1 is transiently induced by changing a culture medium in HepG2 cells. The medium change activated the AhR. However, serum did not influence this induction. They found that tryptophan derivative(s) contained in the autoclaved medium and mild photo-oxidized tryptophan in the medium prepared not fleshly but two weeks earlier contributed to the induction of CYP1A1 by the medium change although the precise chemical nature of these tryptophan compounds was not characterized. In the current study, we used the commercially available, ready-made liquid medium. These findings suggest that the transient induction of CYP1A1 in the control group observed in this study may be due to the medium change rather than serum starvation.

Roth et al. [14] reported that $\Delta^{9}$-THC may induce the expression of CYP1A1 through the AhR due to the lack of inducibility by $\Delta^{9}$-THC in mouse Hepa-1 mutant cells lacking functional AhR or its nuclear translocator genes. Our study with AhR siRNAs showed that CBD induced the expression of human CYP1A1 through the AhR. We also confirmed that the 
induction of CYP1A1 expression by CBD was effectively suppressed by herbimycin A, as was that by omeprazole. Herbimycin A is a PTK inhibitor with selectivity to Src tyrosine kinase [31,32]. Src-family kinases are non-receptor tyrosine kinases that consist of several members including c-Src, Fyn, and Yes [33]. A previous study indicated that at least c-Src did not participate in omeprazole-selective AhR signaling, suggesting the involvement of other PTKs [25]. Omeprazole has been suggested to activate the AhR through the PTK-mediated phosphorylation of $\mathrm{Tyr}^{320}$ in the $\mathrm{AhR}$ [25]. The residue $\mathrm{Tyr}^{320}$ in the AhR, which is located in the PAS-B domain of the ligand-binding domain, may be a potential Src-kinase site. This AhR signaling is omeprazole-selective because 2,3,7,8-tetrachlorodibenzo- $p$-dioxin-mediated AhR activation was not affected by the mutation of $\mathrm{Tyr}^{320}$ in $\mathrm{AhR}$ [25]. The interaction between omeprazole and a cell surface molecule may initiate a signal transduction pathway involving PTKs, leading to activation of the AhR. These results suggest that CBD causes PTK-mediated AhR activation in a ligand-independent manner, similar to omeprazole.

Further experiments were performed to characterize the structural requirements for the inducibility of CYP1A1 expression by CBD. The partial induction of CYP1A1 by olivetol, but not $d$-limonene suggested that the pentylresorcinol structure in CBD was essential for CYP1A1 induction, whereas the whole structure of CBD was required for overall induction. The methylation of either hydroxyl group in CBD failed to induce the expression of CYP1A1. A hydroxyl group at the 2 -position in CBD was equivalent to the hydroxyl group at the 6 -position since there was free rotation of the phenyl ring around the chemical bond at the 1 -position (Fig. 1). These results suggested that both phenolic hydroxyl groups in the 
resorcinol moiety of CBD may be required for CYP1A1 induction.

Most AhR ligands are planar hydrophobic molecules such as $\mathrm{B}[a] \mathrm{P}$ and 3-MC; however, several ligands including omeprazole and bilirubin do not have this characteristic [34]. $\Delta^{9}$-THC and CBN are nearly planar molecules because these phytocannabinoids have a dibenzopyran structure (Fig. 1). On the other hand, CBD has a free rotatable structure between the resorcinol and terpene moieties. Therefore, we initially expected $\Delta^{9}$-THC and $\mathrm{CBN}$ rather than $\mathrm{CBD}$ to be good candidates for AhR ligands in marijuana constituents. However, CBD more potently induced the expression of CYP1A1 than $\Delta^{9}-\mathrm{THC}$ and CBN. Further studies are needed to clarify the mechanism underlying CBD-mediated CYP1A1 induction, involving the direct binding of CBD to the AhR and identification of PTK(s) responsible for this induction.

It has been previously reported that marijuana tar exerts mutagenicity, as assessed by the Ames test $[10,35,36]$. There are a lot of mutagenic and procarcinogenic compounds, such as $\mathrm{B}[a] \mathrm{P}$, in marijuana tar $[9,10]$. For phytocannabinoids contained in marijuana tar, on the other hand, the mutagenicity and carcinogenicity of $\Delta^{9}$-THC, $1 \alpha, 2 \alpha$-epoxyhexahydrocannabinol, and 1S,2R-epoxy-CBD-2,6-diacetate have been shown to be negative [37-42]. However, the majority of phytocannabinoids including CBD have not yet been characterized as mutagen/carcinogen or non-mutagen/non-carcinogen. Further studies are needed to elucidate the mutagenicity and carcinogenicity of CBD besides the biologic response of CBD exposure, such as DNA damage and tumor cell proliferation, both in vitro (i.e. cancer cell culture system) and in vivo (i.e. animal tumor model system). 


\section{Conclusion}

We demonstrated that CBD as well as $\Delta^{9}$-THC induced human CYP1A1 expression. Our results suggest that the induction of CYP1A1 by CBD is mediated through the activation of PTK-dependent AhR signaling. Furthermore, two phenolic hydroxyl groups in the resorcinol moiety of CBD may play pivotal roles in CYP1A1 induction, whereas the whole structure of CBD is essential for overall induction. This study has provided useful information to understand the mechanism underlying CBD-mediated CYP1A1 induction. Further studies are required to determine a role of the phytocannabinoids including $\mathrm{CBD}$ in cancer development induced by marijuana use. 


\section{Conflicts of interest statement}

The authors declare that there are no conflicts of interest. 


\section{Acknowledgements}

This work was supported in part by the Ministry of Education, Culture, Sports, Science, and Technology of Japan [Grant-in-Aid for Young Scientists (B) (grant number 21790135) and Grant-in-Aid for Scientific Research (C) (grant number 20590217)] and by the 'Academic Frontier' Project for Private Universities from the Ministry of Education, Culture, Sports, Science, and Technology of Japan (2005-2009) (grant number 05F016). We thank the RIKEN cell bank (Tsukuba, Japan) for providing the human hepatoma HepG2 cell line and Dr. Tsutomu Matsubara (National Cancer Institute, National Institutes of Health) for his advice. 


\section{References}

[1] W. Hall, L. Degenhardt, Adverse health effects of nonmedical cannabis use, Lancet 374 (2009) 1383-1391.

[2] M.A. ElSohly, D. Slade, Chemical constituents of marijuana: the complex mixture of natural cannabinoids, Life Sci. 78 (2005) 539-548.

[3] R.G. Pertwee, The diverse $\mathrm{CB}_{1}$ and $\mathrm{CB}_{2}$ receptor pharmacology of three plant cannabinoids: $\Delta^{9}$-tetrahydrocannabinol, cannabidiol and $\Delta^{9}$-tetrahydrocannabivarin, $\mathrm{Br}$. J. Pharmacol. 153 (2008) 199-215.

[4] R. Mechoulam, L.A. Parker, R. Gallily, Cannabidiol: an overview of some pharmacological aspects, J. Clin. Pharmacol. 42 (2002) 11S-19S.

[5] S.E. Fligiel, M.D. Roth, E.C. Kleerup, S.H. Barsky, M.S. Simmons, D.P. Tashkin, Tracheobronchial histopathology in habitual smokers of cocaine, marijuana, and/or tobacco, Chest 112 (1997) 319-326.

[6] S.H. Barsky, M.D. Roth, E.C. Kleerup, M. Simmons, D.P. Tashkin, Histopathologic and molecular alterations in bronchial epithelium in habitual smokers of marijuana, cocaine, and/or tobacco, J. Natl. Cancer Inst. 90 (1998) 1198-1205.

[7] Z.F. Zhang, H. Morgenstern, M.R. Spitz, D.P. Tashkin, G.P. Yu, J.R. Marshall, T.C. Hsu, S.P. Schantz, Marijuana use and increased risk of squamous cell carcinoma of the head and neck, Cancer Epidemiol. Biomarkers Prev. 8 (1999) 1071-1078.

[8] M.L. Lee, M. Novotny, K.D. Bartle, Gas chromatography/mass spectrometric and nuclear magnetic resonance spectrometric studies of carcinogenic polynuclear aromatic 
hydrocarbons in tobacco and marijuana smoke condensates, Anal. Chem. 48 (1976) 405-416.

[9] D. Moir, W.S. Rickert, G. Levasseur, Y. Larose, R. Maertens, P. White, S. Desjardins, A comparison of mainstream and sidestream marijuana and tobacco cigarette smoke produced under two machine smoking conditions, Chem. Res. Toxicol. 21 (2008) 494-502.

[10] R.M. Maertens, P.A. White, W. Rickert, G. Levasseur, G.R. Douglas, P.V. Bellier, J.P. McNamee, V. Thuppal, M. Walker, S. Desjardins, The genotoxicity of mainstream and sidestream marijuana and tobacco smoke condensates, Chem. Res. Toxicol. 22 (2009) $1406-1414$.

[11] T. Shimada, Xenobiotic-metabolizing enzymes involved in activation and detoxification of carcinogenic polycyclic aromatic hydrocarbons, Drug Metab. Pharmacokinet. 21 (2006) 257-276.

[12] D. Chakravarti, J.C. Pelling, E.L. Cavalieri, E.G. Rogan, Relating aromatic hydrocarbon-induced DNA adducts and c-H-ras mutations in mouse skin papillomas: the role of apurinic sites, Proc. Natl. Acad. Sci. U. S. A. 92 (1995) 10422-10426.

[13] H. Witschi, B. Saint-François, Enhanced activity of benzpyrene hydroxylase in rat liver and lung after acute cannabis administration, Toxicol. Appl. Pharmacol. 23 (1972) $165-168$.

[14] M.D. Roth, J.A. Marques-Magallanes, M. Yuan, W. Sun, D.P. Tashkin, O. Hankinson, Induction and regulation of the carcinogen-metabolizing enzyme CYP1A1 by marijuana 
smoke and $\Delta^{9}$-tetrahydrocannabinol, Am. J. Respir. Cell Mol. Biol. 24 (2001) 339-344.

[15] T. Sarafian, N. Habib, J.T. Mao, I.H. Tsu, M.L. Yamamoto, E. Hsu, D.P. Tashkin, M.D. Roth, Gene expression changes in human small airway epithelial cells exposed to $\Delta^{9}$-tetrahydrocannabinol, Toxicol. Lett. 158 (2005) 95-107.

[16] S. Takeda, E. Ikeda, S. Su, M. Harada, H. Okazaki, Y. Yoshioka, H. Nishimura, H. Ishii, K. Kakizoe, A. Taniguchi, M. Tokuyasu, T. Himeno, K. Watanabe, C.J. Omiecinski, H. Aramaki, $\Delta^{9}$-THC modulation of fatty acid 2-hydroxylase (FA2H) gene expression: possible involvement of induced levels of PPAR $\alpha$ in MDA-MB-231 breast cancer cells, Toxicology 326 (2014) 18-24.

[17] H. Aramaki, N. Tomiyasu, H. Yoshimura, H. Tsukamoto, Forensic chemical study on marihuana. I. A detection method of the principal constituents by thin-layer and gas chromatographies, Chem. Pharm. Bull. 16 (1968) 822-826.

[18] H. Gohda, S. Narimatsu, I. Yamamoto, H. Yoshimura, In vivo and in vitro metabolism of cannabidiol monomethyl ether and cannabidiol dimethyl ether in the guinea pig: on the formation mechanism of cannabielsoin-type metabolite from cannabidiol, Chem. Pharm. Bull. 38 (1990) 1697-1701.

[19] K. Watanabe, E. Motoya, N. Matsuzawa, T. Funahashi, T. Kimura, T. Matsunaga, K. Arizono, I. Yamamoto, Marijuana extracts possess the effects like the endocrine disrupting chemicals, Toxicology 206 (2005) 471-478.

[20] J. Kim, R.P. Sharma, Calcium-mediated activation of c-Jun $\mathrm{NH}_{2}$-terminal kinase (JNK) and apoptosis in response to cadmium in murine macrophages, Toxicol. Sci. 81 (2004) 
$518-527$.

[21] U.K. Laemmli, Cleavage of structural proteins during the assembly of the head of bacteriophage T4, Nature 227 (1970) 680-685.

[22] K. Kawajiri, Y. Fujii-Kuriyama, Cytochrome P450 gene regulation and physiological functions mediated by the aryl hydrocarbon receptor, Arch. Biochem. Biophys. 464 (2007) 207-212.

[23] H. Kikuchi, A. Hossain, H. Yoshida, S. Kobayashi, Induction of cytochrome P-450 1A1 by omeprazole in human HepG2 cells is protein tyrosine kinase-dependent and is not inhibited by $\alpha$-naphthoflavone, Arch. Biochem. Biophys. 358 (1998) 351-358.

[24] G. Lemaire, C. Delescluse, M. Pralavorio, N. Ledirac, P. Lesca, R. Rahmani, The role of protein tyrosine kinases in CYP1A1 induction by omeprazole and thiabendazole in rat hepatocytes, Life Sci. 74 (2004) 2265-2278.

[25] M. Backlund, M. Ingelman-Sundberg, Regulation of aryl hydrocarbon receptor signal transduction by protein tyrosine kinases, Cell. Signal. 17(2005) 39-48.

[26] L.M. Bornheim, M.A. Correia, Effect of cannabidiol on cytochrome P-450 isozymes, Biochem. Pharmacol. 38 (1989) 2789-2794.

[27] Z. Mehmedic, S. Chandra, D. Slade, H. Denham, S. Foster, A.S. Patel, S.A. Ross, I.A. Khan, M.A. ElSohly, Potency trends of $\Delta^{9}$-THC and other cannabinoids in confiscated cannabis preparations from 1993 to 2008, J. Forensic Sci. 55 (2010) 1209-1217.

[28] A. Ohlsson, J.E. Lindgren, A. Wahlen, S. Agurell, L.E. Hollister, H.K. Gillespie, Plasma delta-9-tetrahydrocannabinol concentrations and clinical effects after oral and 
intravenous administration and smoking, Clin. Pharmacol. Ther. 28 (1980) 409-416.

[29] A. Ohlsson, J.E. Lindgren, S. Andersson, S. Agurell, H.K. Gillespie, L.E. Hollister, Single dose kinetics of cannabidiol in man, in: S. Agurell, W.L. Dewey, R. Willette (Eds.), The Cannabinoids: Chemical, Pharmacologic, and Therapeutic Aspects, Academic Press, New York, 1984, pp. 219-225.

[30] Q. Feng, T. Kumagai, Y. Nakamura, K. Uchida, T. Osawa, Induction of cytochrome P4501A1 by autoclavable culture medium change in HepG2 cells, Xenobiotica 32 (2002) 1033-1043.

[31] Y. Uehara, Y. Murakami, S. Mizuno, S. Kawai, Inhibition of transforming activity of tyrosine kinase oncogenes by herbimycin A, Virology 164 (1988) 294-298.

[32] C.H. June, M.C. Fletcher, J.A. Ledbetter, G.L. Schieven, J.N. Siegel, A.F. Phillips, L.E. Samelson, Inhibition of tyrosine phosphorylation prevents T-cell receptor-mediated signal transduction, Proc. Natl. Acad. Sci. U. S. A. 87 (1990) 7722-7726.

[33] R. Roskoski Jr., Src protein-tyrosine kinase structure and regulation, Biochem. Biophys. Res. Commun. 324 (2004) 1155-1164.

[34] M.S. Denison, A. Pandini, S.R. Nagy, E.P. Baldwin, L. Bonati, Ligand binding and activation of the Ah receptor, Chem. Biol. Interact. 141 (2002) 3-24.

[35] F.W. Busch, D.A. Seid, E.T. Wei, Mutagenic activity of marihuana smoke condensates, Cancer Lett. 6 (1979) 319-324.

[36] F.C. Wehner, S.J. van Rensburg, P.G. Thiel, Mutagenicity of marijuana and Transkei tobacco smoke condensates in the Salmonella/microsome assay, Mutat. Res. 77 (1980) 
$135-142$.

[37] G.F. Van Went, Mutagenicity testing of 3 hallucinogens: LSD, psilocybin and $\Delta^{9}$-THC, using the micronucleus test, Experientia 34 (1978) 324-325.

[38] A.M. Zimmerman, H. Stich, R. San, Nonmutagenic action of cannabinoids in vitro, Pharmacology 16 (1978) 333-343.

[39] H. Glatt, A. Ohlsson, S. Agurell, F. Oesch, $\Delta^{1}$-Tetrahydrocannabinol and $1 \alpha$, $2 \alpha$-epoxyhexahydrocannabinol: mutagenicity investigation in the Ames test, Mutat. Res. 66 (1979) 329-335.

[40] S.H. Berryman, R.A. Anderson Jr., J. Weis, A. Bartke, Evaluation of the co-mutagenicity of ethanol and $\Delta^{9}$-tetrahydrocannabinol with Trenimon, Mutat. Res. 278 (1992) 47-60.

[41] P.C. Chan, R.C. Sills, A.G. Braun, J.K. Haseman, J.R. Bucher, Toxicity and carcinogenicity of $\Delta^{9}$-tetrahydrocannabinol in Fischer rats and B6C3F1 mice, Fundam. Appl. Toxicol. 30 (1996) 109-117.

[42] I. Yamamoto, H. Gohda, S. Narimatsu, K. Watanabe, H. Yoshimura, Cannabielsoin as a new metabolite of cannabidiol in mammals, Pharmacol. Biochem. Behav. 40 (1991) $541-546$. 


\section{Footnotes}

${ }^{1}$ Present address: Laboratory of Xenobiotic Metabolism and Environmental Toxicology,

Faculty of Pharmaceutical Sciences, Hiroshima International University (HIU), 5-1-1

Hiro-koshingai, Kure, Hiroshima 737-0112, Japan. 


\section{Legends for figures}

Fig. 1. Structures of three major phytocannabinoids.

Fig. 2. Effects of major phytocannabinoids on expression of CYP1A1 mRNA in HepG2 cells. (A-C) HepG2 cells $\left(1 \times 10^{6}\right.$ cells/well) were treated with $\Delta^{9}$-THC (A), CBD (B), and CBN (C) for 6 hr. (D) HepG2 cells $\left(1 \times 10^{6}\right.$ cells/well $)$ were treated with or without $25 \mu \mathrm{M} \mathrm{CBD}$ for the indicated periods. Data are expressed as the mean \pm S.D. $(n=3)$.

Fig. 3. Effects of AhR knockdown on induction of CYP1A1 mRNA by 3-MC and CBD in HepG2 cells. HepG2 cells $\left(2 \times 10^{5}\right.$ cells/dish) were transfected with AhR siRNA (ID\# s1199) and incubated for $48 \mathrm{hr}$. (A) AhR expression levels were determined by real-time PCR. Data are expressed as the mean \pm S.D. $(\mathrm{n}=3$ or 4$) . * * p<0.01, * * * p<0.001$ vs control (Dunnett's test). (B) Detection of AhR and actin proteins in the cell lysates (10 $\mu \mathrm{g}$ protein). (C, D) Cells were treated with $10 \mu \mathrm{M} 3-\mathrm{MC}$ for $3 \mathrm{hr}(\mathrm{C})$ and $25 \mu \mathrm{M} \mathrm{CBD}$ for $6 \mathrm{hr}$ (D). CYP1A1 expression levels were determined by real-time PCR. Data are expressed as the mean \pm S.D. (n $=3$ or 4$) .{ }^{* * *} p<0.001$ vs control, \#\#\#p $<0.001$ vs $3-\mathrm{MC}$ or CBD alone (Bonferroni's test).

Fig. 4. Effects of herbimycin A on induction of CYP1A1 mRNA by omeprazole, 3-MC, and CBD in HepG2 cells. HepG2 cells $\left(1 \times 10^{6}\right.$ cells/well $)$ were pretreated with herbimycin A for $12 \mathrm{hr}$. Cells were treated with $50 \mu \mathrm{M}$ omeprazole (A), $10 \mu \mathrm{M} 3-\mathrm{MC}$ (B), or $25 \mu \mathrm{M}$ CBD (C) 
for $6 \mathrm{hr}$. Data are expressed as the mean \pm S.D. $(\mathrm{n}=3) .{ }^{* * *} p<0.001$ vs control, \#\#p $<0.01$, $\# \#$ \# $<0.001$ vs omeprazole, 3-MC, or CBD alone (Bonferroni's test).

Fig. 5. Inducibility of CYP1A1 mRNA by CBD-related compounds in HepG2 cells. (A) Structures of CBD-related compounds. (B) HepG2 cells $\left(1 \times 10^{6}\right.$ cells/well $)$ were treated with each CBD-related compound at $25 \mu \mathrm{M}$ for $6 \mathrm{hr}$. Data are expressed as the mean \pm S.D. $(\mathrm{n}=3$ or 4$) .{ }^{* *} p<0.01,{ }^{* * *} p<0.001$ vs control (Dunnett's test). 


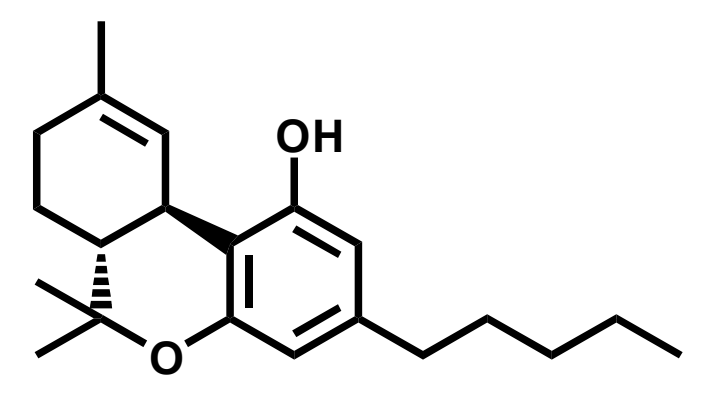

$\Delta^{9}-\mathrm{THC}$

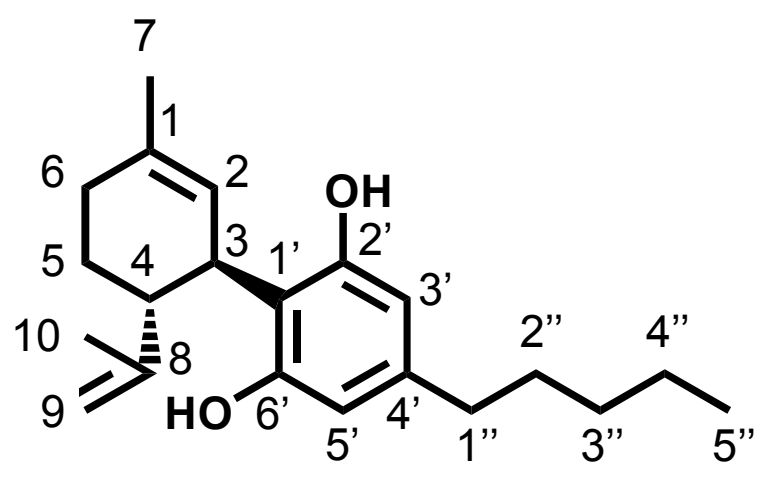

CBD

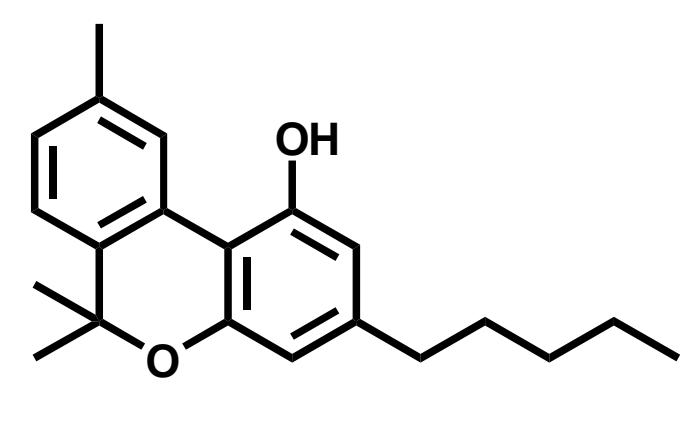

CBN

Fig. 1 
(A)

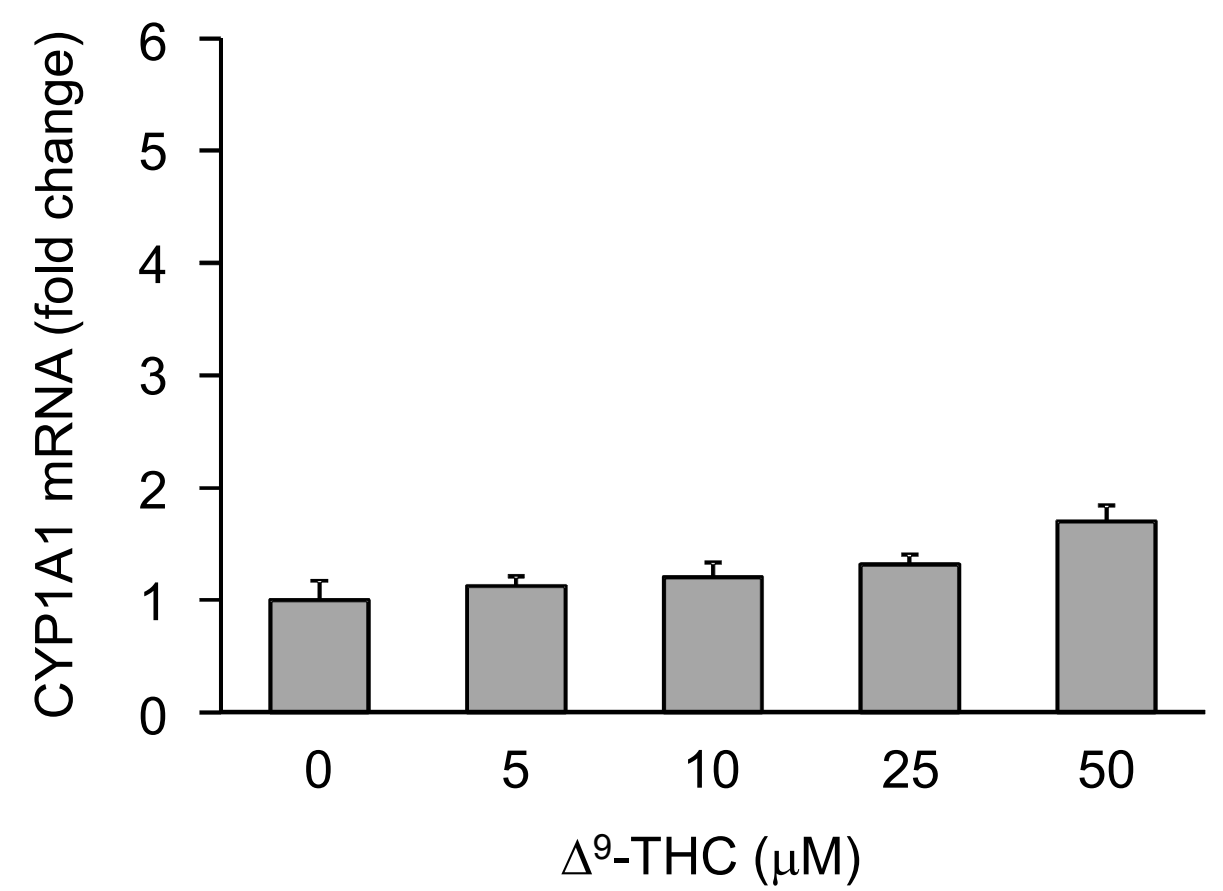

(C)

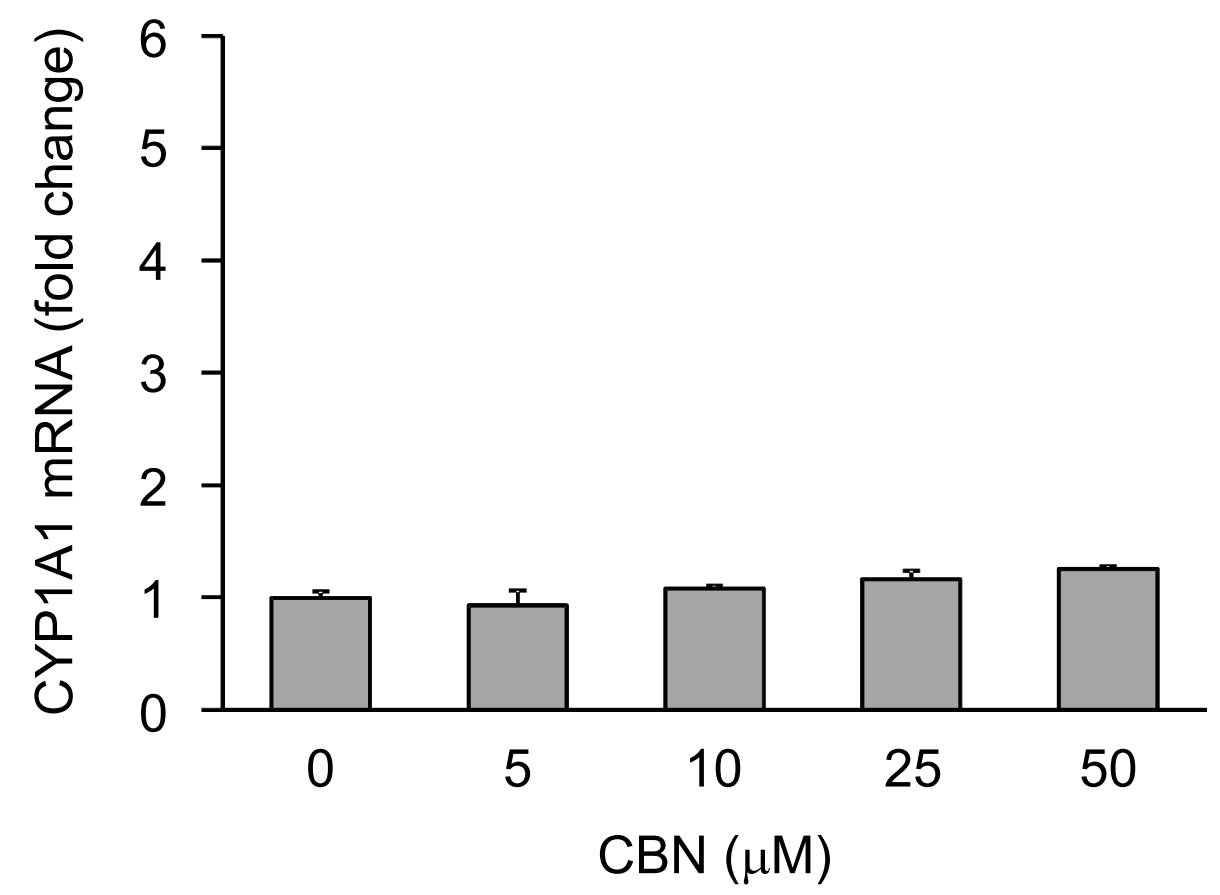

(B)

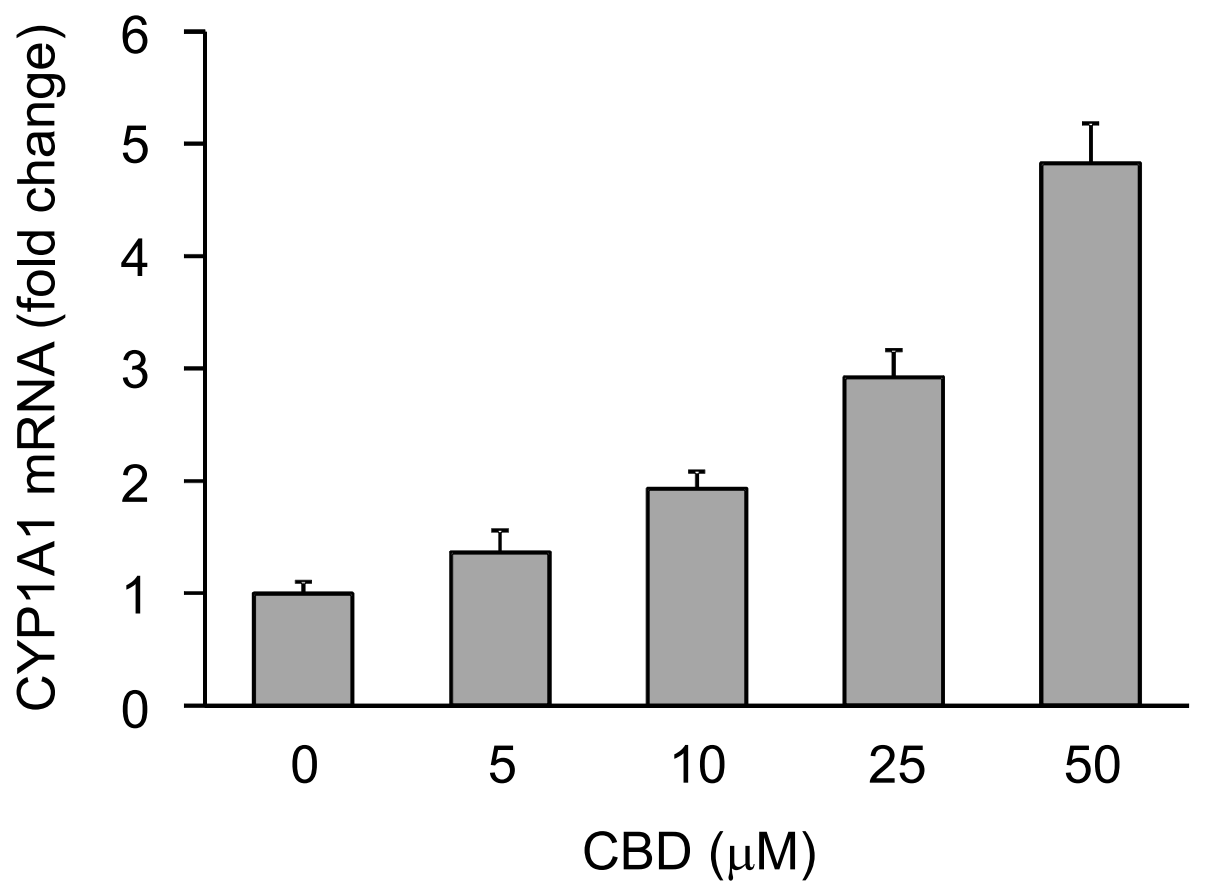

(D)

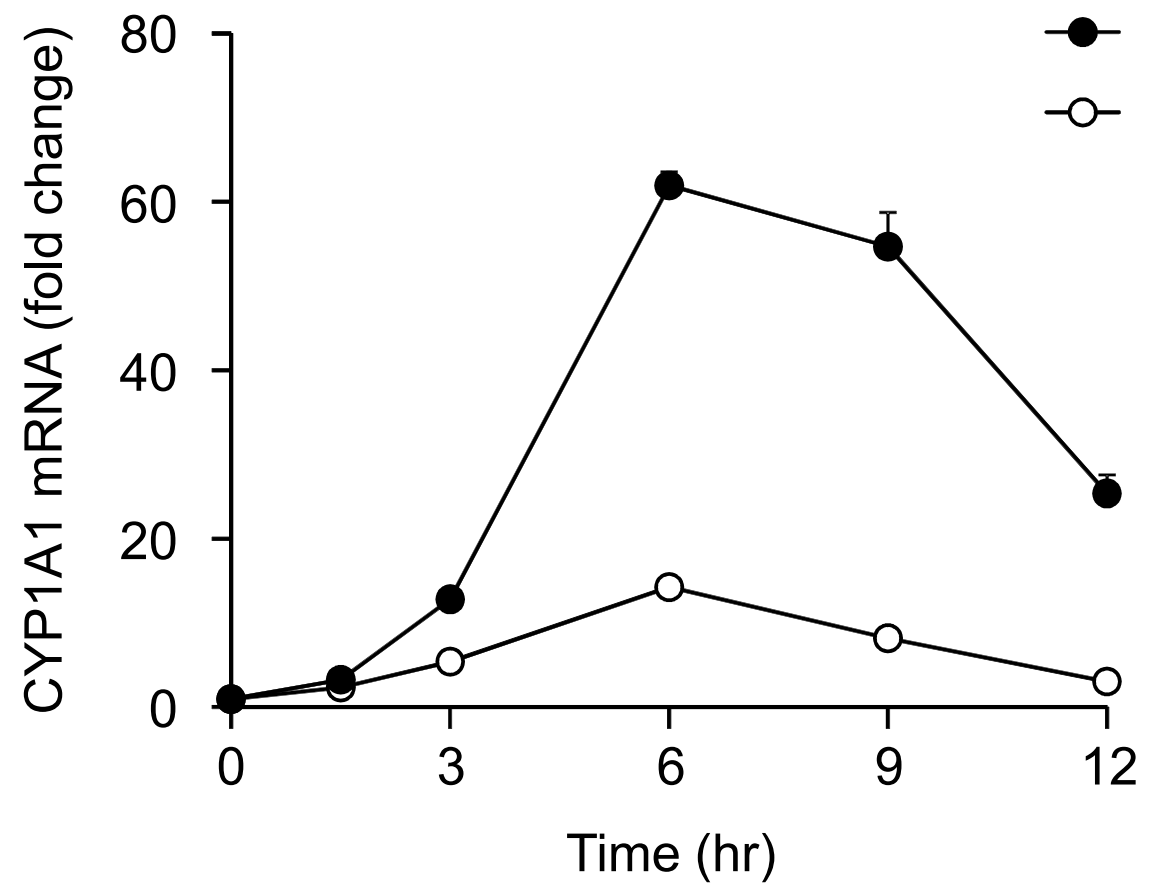

Fig. 2 
(A)

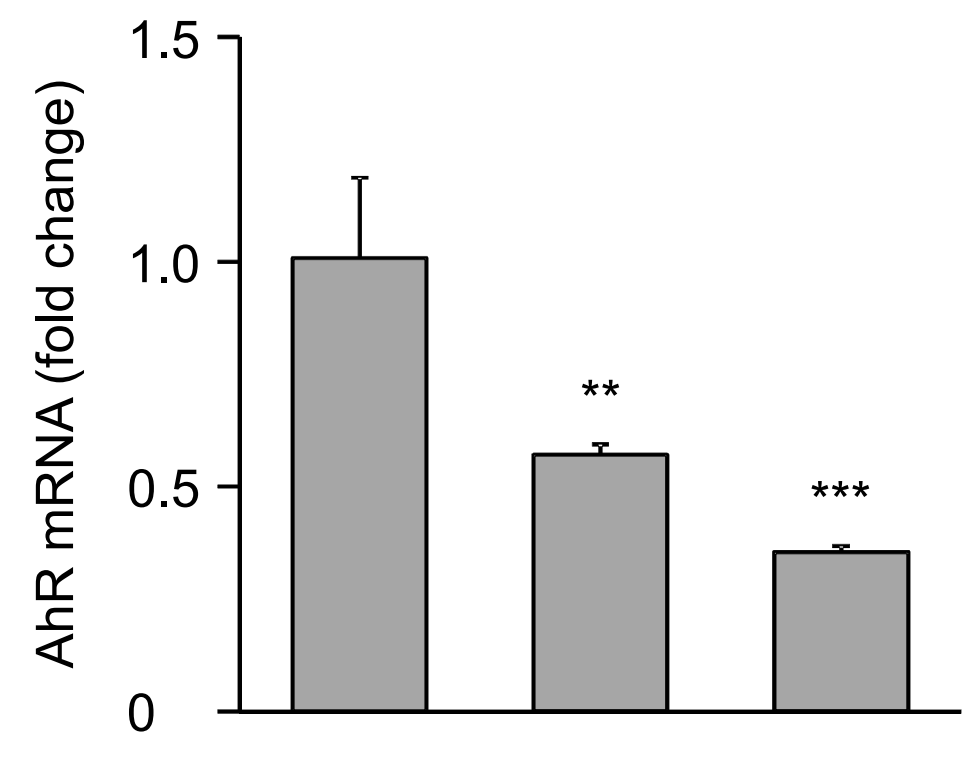

siRNA (nM)

1

(B)

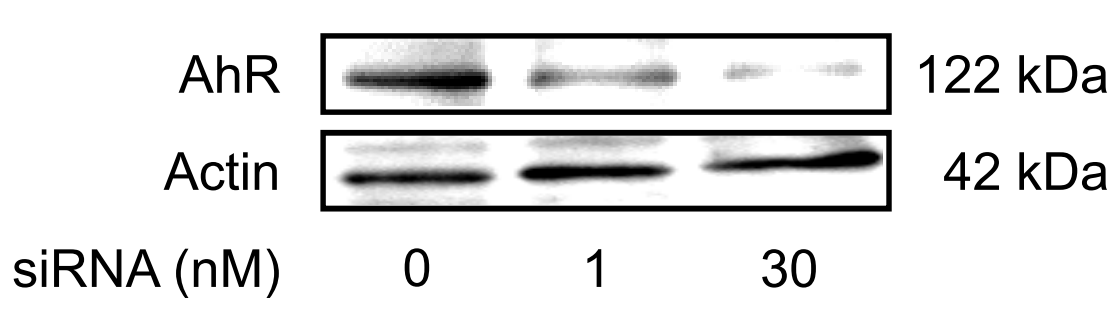

(D)

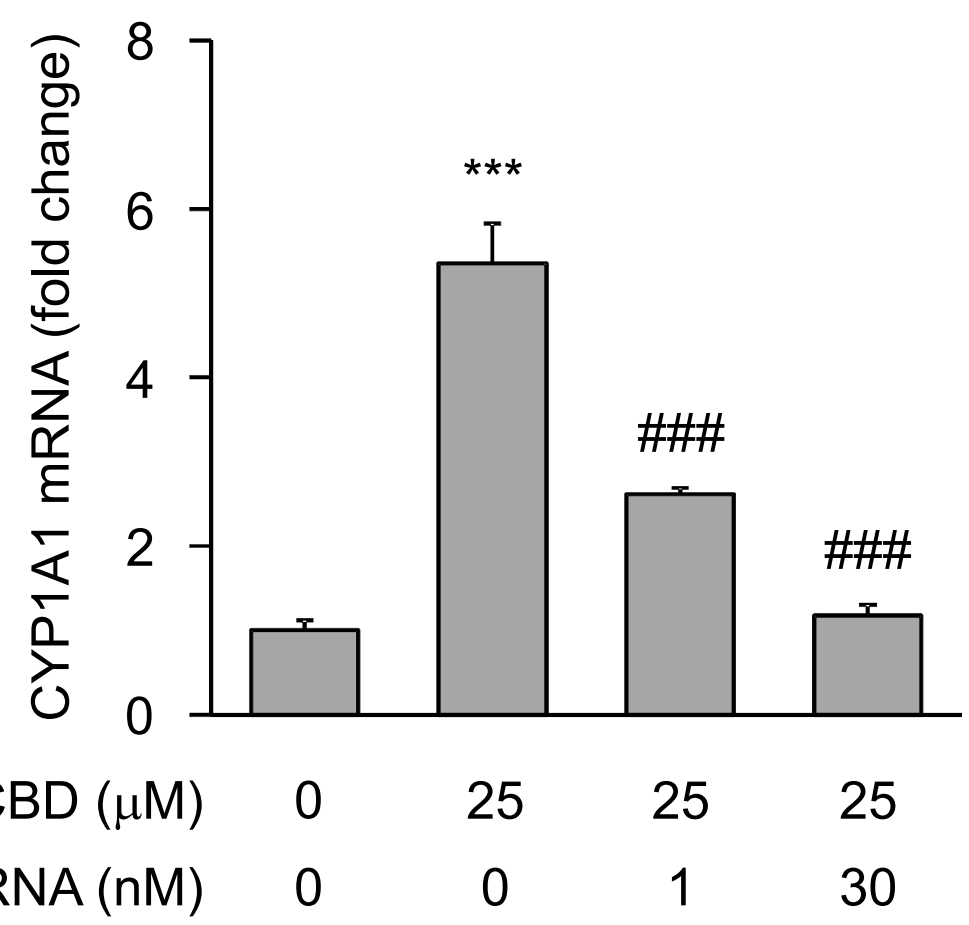

Fig. 3 
(A)

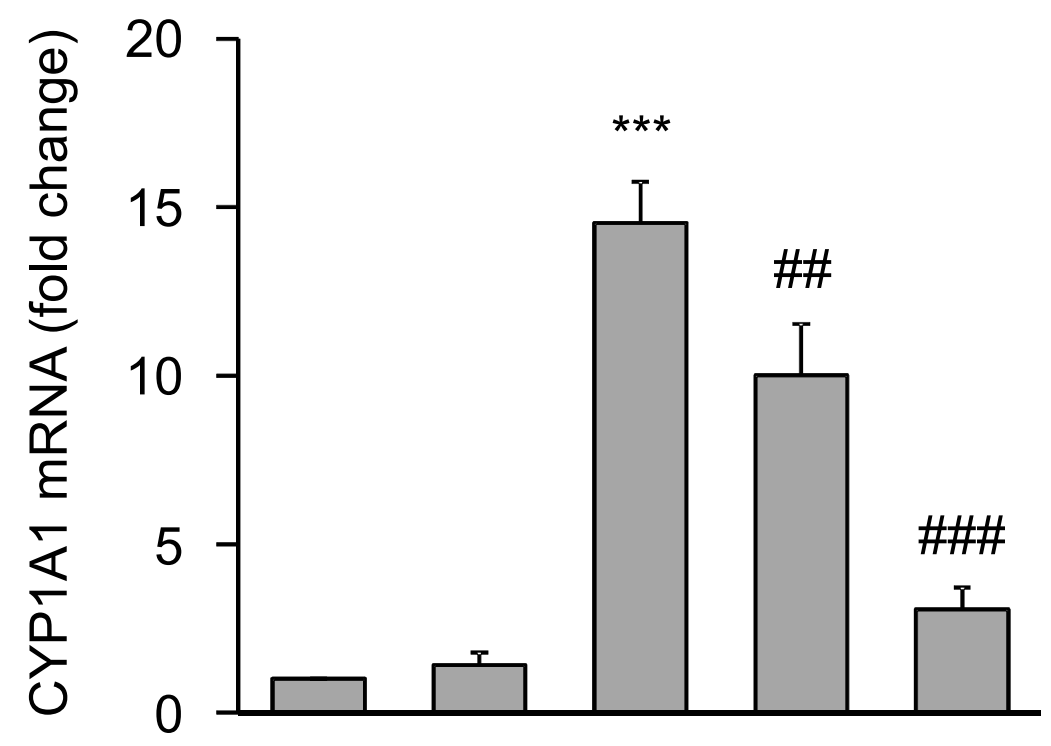

Omeprazole $(\mu \mathrm{M}) \quad 0 \quad 0 \quad \begin{array}{llll}50 & 50 & 50\end{array}$ $\begin{array}{llllll}\text { Herbimycin } \mathrm{A}(\mu \mathrm{M}) & 0 & 0.4 & 0 & 0.08 & 0.4\end{array}$
(B)

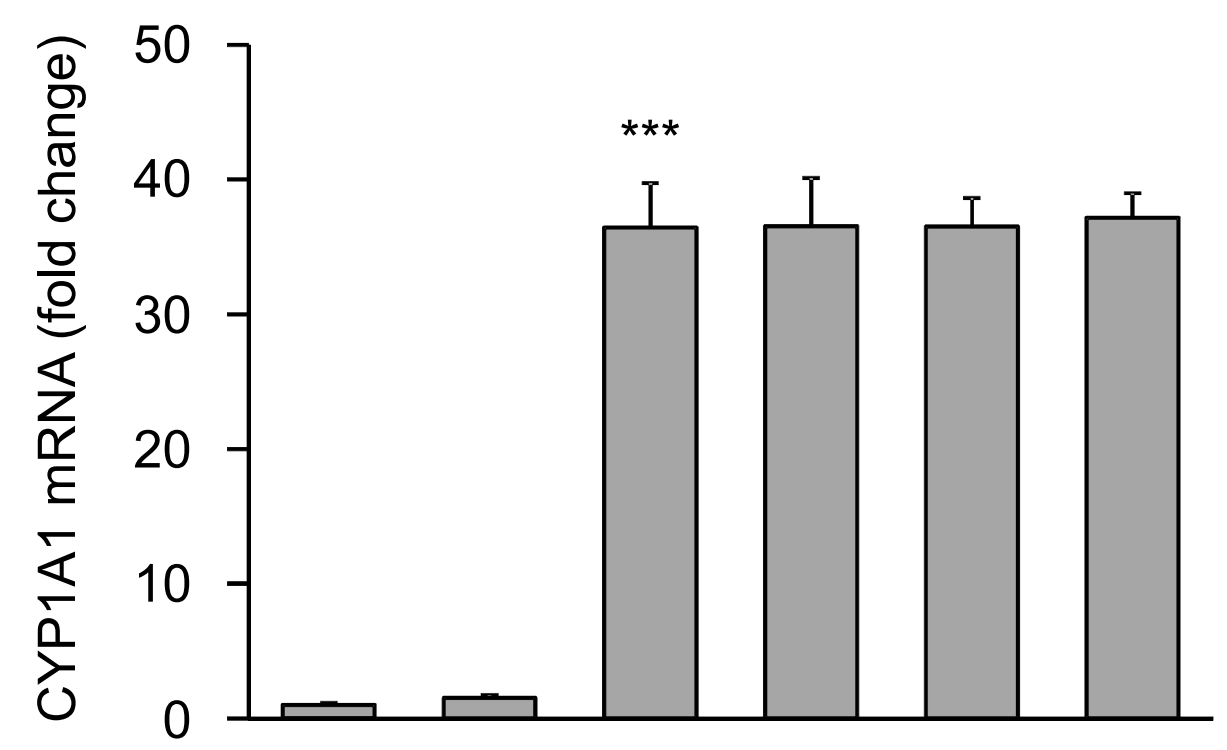

$\begin{array}{lllllll}3-\mathrm{MC}(\mu \mathrm{M}) & 0 & 0 & 10 & 10 & 10 & 10\end{array}$

Herbimycin $A(\mu \mathrm{M}) \quad 0 \quad 0.4 \quad 0 \quad 0.016 \quad 0.08 \quad 0.4$

(C)

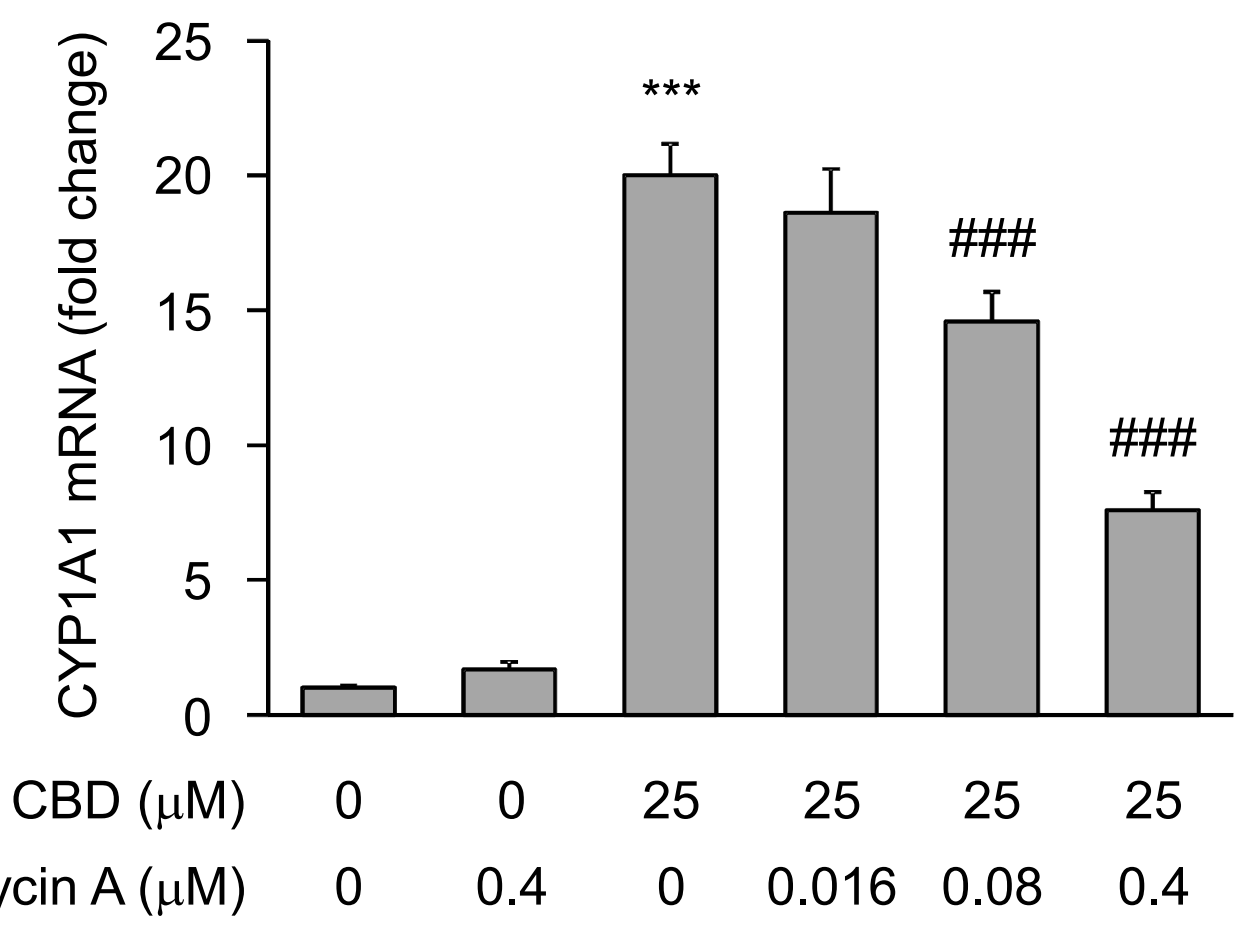

Fig. 4 
(A)

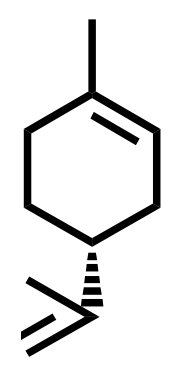

$d$-Limonene

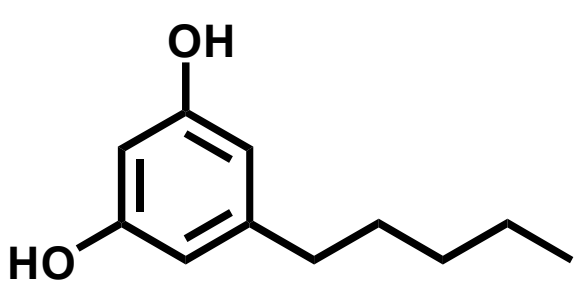

Olivetol

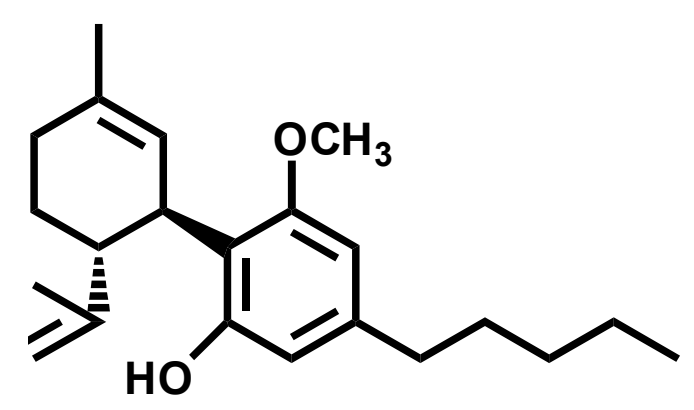

CBDM

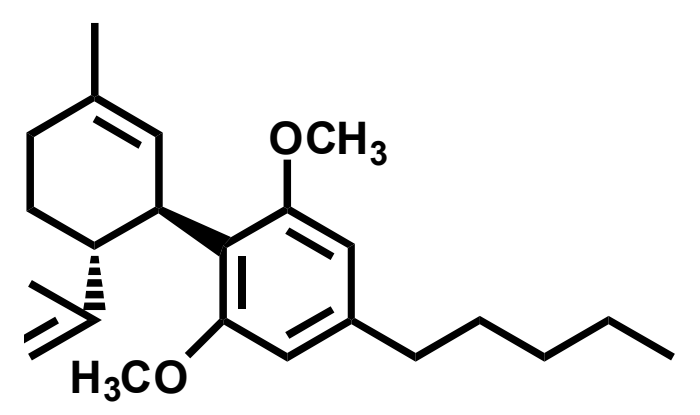

CBDD

(B)

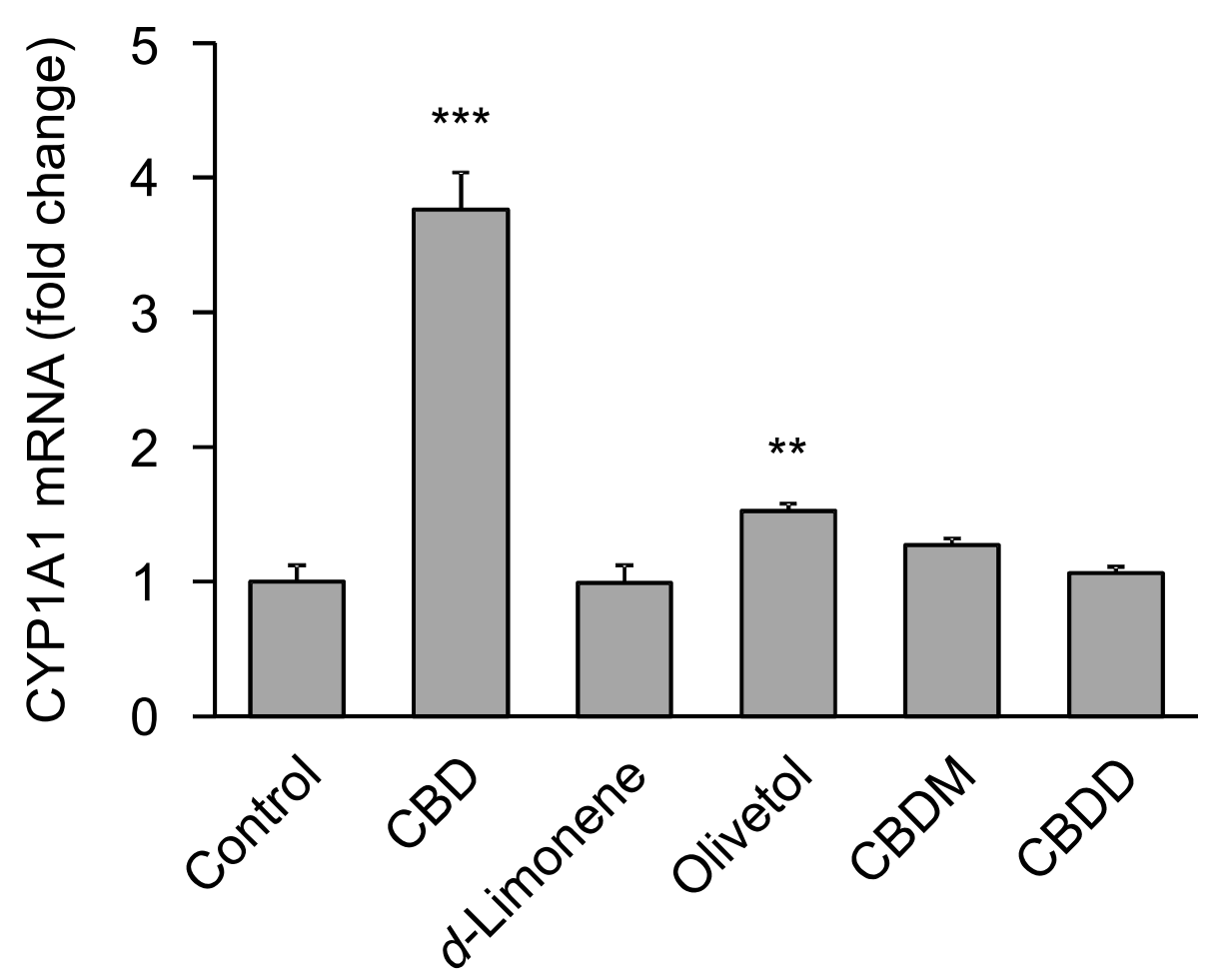

Fig. 5 